\title{
Awareness of ParticipACTION among Canadian adults: a seven-year cross-sectional follow-up
}

\author{
John C. Spence, PhD (1); Guy Faulkner, PhD (2); Eun-Young Lee, PhD (1); Tanya Berry, PhD (1); \\ Christine Cameron, MSc (3); Sameer Deshpande, PhD (4); Amy E. Latimer-Cheung, PhD (5); Ryan E. Rhodes, PhD (6); \\ Mark S. Tremblay, PhD (7)
}

This original quantitative research article has been peer reviewed.

Tweet this article

\begin{abstract}
Introduction: In this cross-sectional follow-up study, we explored Canadian's awareness of ParticipACTION and their levels of physical activity (PA) after seven years of campaigns.

Methods: A population-based survey was conducted with 7282 adults over a period of 14 months from February 2014 to May 2015. The survey consisted of questions on the 2014-2015 Physical Activity Monitor relating to awareness and knowledge of ParticipACTION. Weighted logistic models were constructed to examine whether awareness was associated with PA-related beliefs, intentions, and leisure time physical activity (LTPA).
\end{abstract}

Results: Approximately $20 \%$ of Canadians reported unprompted awareness of ParticipACTION and $82 \%$ reported prompted awareness. Education, income, and having children were significant correlates of awareness among Canadians. The adjusted odds of people being aware of ParticipACTION (prompted \& unprompted) were greater if they were more educated $(\mathrm{OR}=1.57,95 \% \mathrm{CI}: 1.04-2.39$; OR $=2.00,95 \% \mathrm{CI}$ : 1.24-3.24), reported higher income (OR $=3.92$, 95\% CI: $2.35-6.53$; OR $=2.29,95 \%$ CI: $1.44-3.62)$, and had children (OR $=1.93,95 \% \mathrm{CI}: 1.40-2.66$; OR $=1.70,95 \% \mathrm{CI}$ : 1.26-2.30). Furthermore, awareness of ParticipACTION was positively associated with outcome expectations and self-efficacy, and negatively associated with LTPA status.

Conclusion: Levels of unprompted awareness of ParticipACTION are higher than previously reported and, in comparison to active Canadians, inactive Canadians are more likely to be aware of the organization. Given that it had primarily targeted parents of inactive children over the past seven years, it appears the organization has been partially effective in achieving its communication goals.

Keywords: mass media, physical activity, self-efficacy, behaviour change

\section{Introduction}

The vast majority of Canadian adults are physically inactive and spend most of their waking hours sitting. ${ }^{1}$ In contrast, engaging in regular physical activity is beneficial to health in many ways including prevention of chronic diseases such as type 2 diabetes, cardiovascular disease, breast cancer, and mental illness. ${ }^{2}$ For instance, in comparison to smoking, poor diet, and excess alcohol consumption, physical inactivity is the leading behavioural risk factor of all-cause mortality for Canadian women (attributable life expectancy loss of 3 years) and second only to smoking for Canadian men. ${ }^{3}$ Furthermore, variations in prevalence of health behaviours
Highlights

- Canadians continue to demonstrate high levels of awareness of ParticipACTION.

- Those who are aware of the organization are more likely to have children, and be inactive but hold positive beliefs about physical activity.

- The efforts of the relaunched ParticipACTION may have resonated with inactive Canadian adults through campaigns about children.

- Large knowledge gaps in awareness continue to be associated with levels of education and household income. Thus, future physical activity campaigns, programs, and policy initiatives should attempt to target different segments of the population, especially people who are disadvantaged.

such as physical activity partially explain the well-documented association between income status and life expectancy in the US. ${ }^{4}$ A recent economic analysis estimated that if $10 \%$ of inactive Canadians could be persuaded to be more physically active and sit less, a cost-savings to the health care system of approximately $\$ 2.6$ billon could be achieved by $2040 . .^{5}$ Thus, the individual and societal benefits of a physically active population are very clear. The challenge, however, is identifying effective

Author references:

1. Faculty of Kinesiology, Sport, and Recreation, University of Alberta, Edmonton, Alberta, Canada

2. School of Kinesiology, University of British Columbia, Vancouver, British Columbia, Canada

3. Canadian Fitness and Lifestyle Research Institute, Ottawa, Ontario, Canada

4. Faculty of Management, University of Lethbridge, Lethbridge, Alberta, Canada

5. School of Kinesiology and Health Studies, Queen's University, Kingston, Ontario, Canada

6. School of Exercise Science, Physical and Health Education, University of Victoria, Victoria, British Columbia, Canada

7. Healthy Active Living and Obesity Research Group, Children's Hospital of Eastern Ontario Research Institute, Ottawa, Ontario, Canada

Correspondence: John C. Spence, Sedentary Living Lab, Faculty of Kinesiology, Sport, and Recreation, 3-113 Van Vliet Complex, University of Alberta, Edmonton, AB T6G 2H9; Tel: 780-492-1379; Fax: 780-492-2364; Email: jc.spence@ualberta.ca 
interventions and programs that can elicit and maintain changes in population-level physical activity.

Media campaigns have long been thought to increase awareness, knowledge, and beliefs about physical activity. ${ }^{6,7}$ Though some debate exists about the effectiveness of stand-alone media campaigns for increasing population physical activity, ${ }^{8,9}$ such campaigns can be an effective tool for promoting physical activity when incorporated with community programs. ${ }^{10}$ In its original structure (1971-2001), ParticipACTION was a social marketing and communications organization that promoted physical activity in Canada, primarily through media campaigns. ${ }^{11-13}$ After a brief hiatus, it was relaunched in 2007 with the mandate to continue its campaigns and to engage in capacity building and knowledge exchange. ${ }^{13}$ From the late 1970 s to the early 2000s, it enjoyed high levels of recognition among Canadians with prompted awareness of its logo or messages ranging from $77 \%$ to $80 \% .^{14}$ Despite a six-year hiatus in operations, in 2007, Canadians still reported $82 \%$ prompted awareness and $8 \%$ unprompted awareness of ParticipACTION. ${ }^{15}$

The "new" ParticipACTION soon shifted its focus from all Canadians to a targeted approach of promoting the physical activity of Canadian children. Specifically, it targeted parents-mothers in particularof inactive children. A majority of Canadian children were inactive ${ }^{16}$ but a majority of parents also believed their children were sufficiently physically active. ${ }^{17,18}$ This disconnect was addressed primarily through education and information. First, the "Inactive Kids" campaign was launched in October of 2007 to increase awareness about the negative health effects associated with the low levels of physical activity observed among Canadian children. This was then followed by the "Think Again" campaign in 2011 to challenge mothers to reconsider whether their children were meeting the existing physical activity guidelines. ${ }^{19}$ The "Bring Back Play" campaigns then provided potential solutions or options for parents to facilitate the active play of their children. Parents who were aware of the "Think Again" campaign showed greater knowledge of the physical activity guidelines, had stronger intentions to help their children meet the guidelines, and engaged in more parental support behaviours for their children's physical activity. ${ }^{20,21}$ Taken together, these are good examples of a set of focused campaigns that also encouraged further examination of the factors that influence parental support for children's active play and physical activity. 17,18,22-24 Based on measures of media impressions (e.g. Gross Rating Points) and recall surveys, many Canadians were exposed to these campaigns. ${ }^{13}$ The question remained whether all Canadians were paying attention to the efforts of ParticipACTION.

Prior to the relaunch of ParticipACTION in 2007, and as a baseline, we surveyed Canadians about their knowledge and awareness of the organization. ${ }^{15}$ This research was guided by the hierarchy-ofeffects model (HOEM), ${ }^{25}$ which assumes that media campaigns influence behaviour through a sequence of stages of awareness and intermediary outcomes (e.g. knowledge, beliefs). We found that levels of awareness of ParticipACTION were associated with beliefs about physical activity (outcome expectations, selfefficacy, intention), leisure-time physical activity (LTPA), and that knowledge gaps in awareness existed for those at lower levels of education and income.

In light of the many campaigns and knowledge exchange initiatives that the 'new' ParticipACTION has conducted since 2007, we replicated our baseline study to assess whether and how its efforts had impact on the knowledge, beliefs, and physical activity of Canadian adults. Therefore, the purposes of this cross-sectional study were to: (a) determine the awareness of ParticipACTION among Canadians; (b) confirm if awareness of ParticipACTION among Canadians still varied as a function of education and income levels; and, (c) examine whether awareness of ParticipACTION was associated with PA-related beliefs, intentions, and LTPA as suggested by the HOEM. Specifically, we tested a model including awareness of ParticipACTION (unprompted, prompted), outcome expectations, selfefficacy, intention, and LTPA status. We hypothesized that people who were aware of ParticipACTION would be more likely to be physically active and to hold more positive beliefs about being physically active.

\section{Methods}

\section{Participants and procedures}

To assess awareness of ParticipACTION on the part of Canadians, a population-based survey was conducted on a monthly basis over a period of 14 months from February 2014 to May 2015. The survey consisted of questions that were added to the 20142015 Physical Activity Monitor (PAM) conducted by the Institute for Social Research at York University and Advanis Jolicoeur on behalf of the Canadian Fitness and Lifestyle Research Institute. The sample was selected on a probability basis proportional to the size of the population in the provinces and territories, with an over-sample in small provinces. For the 2014-2015 PAM, Canadians 18 years of age and older were cross-sectionally sampled per month across all provinces and territories. This on-going rolling sampling process yielded a nationally representative sample of 7282 adults with a response rate of $26 \%$ to $30 \%$. We reported our findings based on the aggregate sample. In the past, non-response has not been related to the subject matter in the PAM. ${ }^{26}$

The PAM employs a telephone-based survey with random-digit dialing, using Computer-Assisted Telephone Interviewing (CATI) software. Specifically, a multi-stage probability selection process was used to select a survey respondent who was 18 years of age or older in the household. Once a potential respondent within a household was chosen, no other person within that same household could participate in the survey. Institute for Social Research administered the surveys in either French or English. Study procedures were approved by the research ethics board at the University of Alberta.

\section{Measures}

Apart from the addition of a question on whether the respondent had children (child status), this study included the same set of measures as were analyzed in $2007 . .^{15}$

\section{Demographics}

Information was collected on participants' sex, age, annual gross household income, level of education (high school or less, college, university), and child status.

\section{Physical activity beliefs}

Self-efficacy was measured using a single seven-point scale asking "how confident are you that you can regularly do a total of 30 minutes or more of moderate physical activity per day at least three or four times a week?" Response options ranged from 
'not at all confident' to 'very confident'. Outcome expectations were measured with three items on a seven-point scale asking about beliefs that regular physical activity will help reduce stress, prevent heart disease, and maintain activities of daily living. Response options ranged from 'do not agree' to 'agree very strongly'. These items were then aggregated to create a mean score (Cronbach's alpha $=.72$ ). Intention to be physically active was measured with a single sevenpoint scale asking "thinking ahead over the next six months, to what extent do you intend to be physically active?" Response options ranged from 'no intention at all' to 'fully intend'.

\section{Awareness of ParticipACTION}

Unprompted awareness and prompted awareness of ParticipACTION were assessed. For unprompted awareness, participants were asked "When you think of physical fitness, what group or organization promoting fitness in Canada comes to mind?" For prompted awareness, participants were then asked if they were aware of the following programs and/or campaigns as potential sources of physical activity information including Canada's Physical Activity Guide, Canada's Food Guide, and ParticipACTION. A similar method was adopted in previous studies. ${ }^{14,15,27}$

\section{Physical activity}

LTPA over the past 12 months was assessed using an adaptation of the Minnesota Leisure Time Physical Activity Questionnaire. ${ }^{28}$ Participants indicated which activities they had undertaken in the previous year (up to 30 activities), the frequency, and the average time spent in each. Average daily LTPA was calculated as follows: LTPA (Metabolic equivalent or MET hours $)=\Sigma\left(N \_i \times\right.$ D_i $\times$ METs_i/365), where $\mathrm{N}$ is the number of times the activity was performed in the past 12 months, $\mathrm{D}$ is the average duration in hours, and METs is the estimated energy cost $\left(\mathrm{kJ} \times \mathrm{kg}^{-1} \times \mathrm{hr}^{-1}\right)$. Respondents were classified as being active if they achieved 3.0 MET-hours or more per day of LTPA, ${ }^{29}$ which is roughly equivalent to walking for 60 minutes on a daily basis. All others were classified as being inactive.

\section{Statistical analysis}

Statistical analyses were completed using SAS 9.4 (SAS Institute Inc., Cary, NC). Frequencies were calculated for the awareness variables and associations between the sociodemographic variables and LTPA status. Chi square statistics were performed to examine the differences in distribution of gender, age, household income, level of education, and LTPA status by prompted and unprompted awareness of ParticipACTION with significance assessed at $p<0.05$ (purposes a and b). To examine the associations between awareness of ParticipACTION (prompted and unprompted) and socioeconomic status (household income, level of education), binary logistic regression models were conducted after adjusting for gender and age (purpose b). To test the HOEM (purpose c), a series of one-way between-subject ANCOVAs using the PROC GLM procedure were performed with ParticipACTION awareness (prompted and unprompted) being the independent variable and outcome expectations, self-efficacy, and intention with type of awareness being the dependent variables. Gender and age were entered as covariates. Last, two hierarchical logistic regression models were created to model the associations between LTPA, beliefs and awareness variables, while adjusting for potential covariates. Specifically, the first step included age, gender, education, income, and awareness of ParticipACTION (prompted or unprompted), followed by outcome expectations and self-efficacy in step 2, with intention entered in step 3 . Based on tolerance and variance inflation factors, no issues with multicollinearity were apparent. ${ }^{30}$ All analyses were weighted to reflect the sample design, and the distribution of age and gender among Canadians.

\section{Results}

Approximately $47 \%$ of respondents were categorized as being active, $82.2 \%$ were aware of ParticipACTION when prompted, and $20.3 \%$ identified it as the organization that comes to mind when they think of promotion of physical fitness (see Table 1 ). When prompted about other programs and campaigns, $92 \%$ of respondents were aware of Canada's Food Guide while $37 \%$ indicated they were aware of Canada's Physical Activity Guide (data not shown).

No significant gender differences existed for either prompted or unprompted awareness of ParticipACTION. Age was associated with awareness; specifically, the youngest group of respondents appeared less likely to report prompted awareness than any other age group. Conversely, the oldest group of respondents appeared less likely to report unprompted awareness in comparison to those 25 to 44 years and those 45 to 64 years. In addition, similar patterns of awareness were observed for both household income and level of education with those at the lowest levels being less aware of ParticipACTION than those at the higher levels. Regardless of awareness type, people with children were more likely to be aware of ParticipACTION. Finally, those who were classified as being inactive were more likely to cite unprompted awareness of ParticipACTION. Education, income, and having children remained significantly associated with unprompted and prompted awareness of ParticipACTION respectively, even after adjusting for age and gender (see Table 2). For instance, in comparison to those earning $<\$ 30000$, those Canadians earning $>\$ 60000$ per year were much more likely to be aware of ParticipACTION either unprompted $(\mathrm{OR}=2.29,95 \% \mathrm{CI}$ : 1.44-3.62) or prompted (OR $=3.92,95 \%$ CI: 2.35-6.53)

To examine the utility of the HOEM in relation to LTPA status, we first conducted a series of one-way ANCOVAs to determine if outcome expectations, self-efficacy, and intention for physical activity varied with level of awareness for ParticipACTION. After adjusting for covariates, self-efficacy $(\mathrm{F}[1,3577]=13.93$, $p<.0001$, partial $\eta$-squared $=.004$ ) varied significantly with unprompted awareness of ParticipACTION. No such effects were observed for outcome expectations or intention. For prompted awareness of ParticipACTION, outcome expectations $(F[1,7193]=52.44, p<.0001$, partial $\eta$-squared $=.007$ ) varied significantly by awareness. No such effects were observed for self-efficacy or intention. Though the adjusted marginal means show that higher levels of self-efficacy were held by those who had unprompted awareness of ParticipACTION, and higher levels of outcome expectations were held by those who were aware of ParticipACTION prompted (Table 3 ), the effects were very small.

When LTPA status was regressed on the beliefs and awareness variables associated with the HOEM (see Table 4), both selfefficacy and intention were significant covariates regardless of the awareness type. Unprompted awareness was a significant covariate of LTPA. Specifically, if a person was aware of ParticipACTION, the 
TABLE 1

Association between sociodemographic factors and awareness of ParticipACTION among Canadian adults

\begin{tabular}{|c|c|c|c|c|c|c|c|c|}
\hline & \multicolumn{8}{|c|}{ Awareness of ParticipACTION } \\
\hline & \multicolumn{2}{|c|}{ Total sample } & \multicolumn{3}{|c|}{ Prompted awareness } & \multicolumn{3}{|c|}{ Unprompted awareness } \\
\hline & $\mathbf{N}$ & $\%$ & $\mathbf{n}$ & $\%$ & $p$ & $\mathbf{n}$ & $\%$ & $p$ \\
\hline Overall & 7279 & 100 & 6526 & 82.2 & & 816 & 20.3 & \\
\hline \multicolumn{9}{|l|}{ Gender } \\
\hline Male & 2920 & 48.4 & 2602 & 83.2 & & 326 & 21.6 & \\
\hline Female & 4359 & 51.6 & 3922 & 81.1 & & 490 & 19.0 & \\
\hline \multicolumn{9}{|l|}{ Age (years) } \\
\hline $18-24$ & 284 & 25.4 & 169 & 61.3 & & 5 & 0.1 & \\
\hline $25-44$ & 1705 & 29.0 & 1497 & 85.2 & & 228 & 26.1 & \\
\hline $45-64$ & 3199 & 31.5 & 3030 & 93.8 & & 462 & 25.6 & \\
\hline $65+$ & 2091 & 14.1 & 1828 & 86.9 & $<.0001$ & 121 & 15.1 & $<.0001$ \\
\hline \multicolumn{9}{|c|}{ Annual gross household income (\$) } \\
\hline$<30000$ & 923 & 12.0 & 762 & 68.5 & & 47 & 13.2 & \\
\hline $30000-59999$ & 1500 & 24.1 & 1346 & 79.7 & & 134 & 13.2 & \\
\hline $60000+$ & 3327 & 63.9 & 3125 & 88.7 & $<.0001$ & 519 & 25.2 & $<.0001$ \\
\hline \multicolumn{9}{|l|}{ Level of education } \\
\hline High school or less & 2151 & 30.7 & 1793 & 77.4 & & 115 & 13.8 & \\
\hline College & 2048 & 30.4 & 1865 & 82.4 & & 215 & 19.6 & \\
\hline University & 3026 & 38.9 & 2828 & 85.9 & & 484 & 24.5 & $<.01$ \\
\hline \multicolumn{9}{|l|}{ Child status } \\
\hline No children & 5911 & 80.0 & 5269 & 89.3 & & 605 & 18.3 & \\
\hline Children & 1368 & 20.0 & 1255 & 80.3 & $<.0001$ & 211 & 26.3 & $<.001$ \\
\hline \multicolumn{9}{|l|}{ LTPA status } \\
\hline Inactive & 4040 & 53.0 & 3591 & 84.2 & & 467 & 23.4 & \\
\hline Active & 2944 & 47.0 & 2668 & 79.8 & & 326 & 17.2 & $<.05$ \\
\hline
\end{tabular}

Abbreviation: LTPA, leisure time physical activity.

Note: All percentages represent weighted data.

odds of him/her being physically active decreased by a factor of 0.35 .

\section{Discussion}

ParticipACTION is a social marketing and communications organization that has promoted physical activity in Canada for most of the past 45 years. ${ }^{13,14}$ After a brief hiatus, it was relaunched in 2007. We found that approximately $20 \%$ of Canadians were aware of ParticipACTION unprompted and $82 \%$ were aware when prompted. The levels of prompted awareness were similar to 2007. But, in comparison to rates of unprompted awareness of $8 \%$ in $2007,{ }^{15}$ this reflects a potential increase in "top of mind" awareness of ParticipACTION between 2007 and 2014. The demographic patterns in awareness were similar from 2007 to 2014 except that inactive respondents had greater unprompted awareness of ParticipACTION than active ones in
2014 and a much larger proportion of women reported unprompted awareness in 2014 (6.7\% vs. 19\%). Furthermore, in 2014, respondents with children were more likely to be aware of ParticipACTION than respondents without. Comparison of parents to non-parents was not assessed in 2007. Given the explicit focus of ParticipACTION's communications on targeting parents of inactive children, this finding provides evidence for the ability of mass media marketing physical activity initiatives to segment audiences on the basis of their demographic profile and offer targeted communications. ${ }^{31}$ Others have suggested such segmentation may be difficult if the item or issue being sold or promoted has a broad, universal appeal, such as health promotion. ${ }^{32}$ Our results suggest ParticipACTION were successful in reaching their target audience of parents.
The second purpose of this study was to determine if knowledge gaps in awareness of ParticipACTION existed and if these gaps were differentially related to household education and income. As was the case in $2007,{ }^{15}$ the odds of people being aware of ParticipACTION were greater if they were more educated and reported higher income. These findings are consistent with the knowledge gap deficit model which suggests that the higher the education of an individual the higher his/her motivation to attend to health messages. ${ }^{33,34}$ Given that upwards of $30 \%$ of the education gradient in health behaviours is explained by knowledge and cognitive ability, ${ }^{35}$ attempting to reduce these knowledge gaps and enhancing physical literacy should be a public health priority. ${ }^{36}$ Consistent with these findings, information and public education targeted by education and income levels are one of 
TABLE 2

Weighted associations between awareness of ParticipACTION (unprompted and prompted) and demographic covariates ${ }^{\mathrm{a}}$

\begin{tabular}{|c|c|c|c|c|}
\hline & \multicolumn{4}{|c|}{ Awareness of ParticipACTION } \\
\hline & \multicolumn{2}{|c|}{ Prompted } & \multicolumn{2}{|c|}{ Unprompted } \\
\hline & OR & $95 \% \mathrm{Cl}$ & OR & $95 \% \mathrm{Cl}$ \\
\hline \multicolumn{5}{|c|}{ Annual gross household income (\$) } \\
\hline$<30000$ & \multicolumn{2}{|c|}{1 (reference) } & \multicolumn{2}{|c|}{1 (reference) } \\
\hline $30000-59999$ & 1.94 & $1.07-3.52^{*}$ & 0.96 & $0.58-1.61$ \\
\hline $60000+$ & 3.92 & $2.35-6.53^{*}$ & 2.29 & $1.44-3.62^{*}$ \\
\hline \multicolumn{5}{|l|}{ Level of education } \\
\hline High school or less & \multicolumn{2}{|c|}{1 (reference) } & \multicolumn{2}{|c|}{1 (reference) } \\
\hline College & 1.37 & $0.88-2.15$ & 1.51 & $0.91-2.52$ \\
\hline University & 1.57 & $1.04-2.39^{*}$ & 2.00 & $1.24-3.24^{*}$ \\
\hline \multicolumn{5}{|l|}{ Child status } \\
\hline No children & \multicolumn{2}{|c|}{1 (reference) } & \multicolumn{2}{|c|}{1 (reference) } \\
\hline Children & 1.93 & $1.40-2.66^{*}$ & 1.70 & $1.26-2.30^{*}$ \\
\hline
\end{tabular}

Abbreviations: $\mathrm{CI}$, confidence interval; OR, odds ratio.

${ }^{a}$ Adjusted for gender and age.

${ }^{*} p<.05$.

four areas of focus in a proposed physical activity plan for Canada. ${ }^{37}$

The final purpose of this study was to determine if awareness of ParticipACTION was associated with physical activity related beliefs, intentions, and physical activity. Outcome expectations (prompted) and self-efficacy (unprompted) varied significantly by awareness. Similar to 2007, the sizes of the effects were very small, suggesting that other factors influence the beliefs and intention for physical activity apart from awareness. These findings do support the HOEM such that increased awareness is associated with more positive social cognitions. However, an alternate interpretation that cannot be ruled out due to the cross-sectional nature of the study is that respondents with more positive perceptions of physical activity (e.g. self-efficacy, outcome expectations) are more attune to physical activity messaging.

Awareness of ParticipACTION was also associated with LTPA status. However, findings were contrary to what we had hypothesized. Specifically, inactive Canadians were more aware of ParticipACTION regardless of awareness type. This finding is counter to the suggestion that people who are active or hold more positive perceptions of physical activity are more attune to physical activity messages. ${ }^{38}$ Rather, perhaps this demonstrates that the campaigns and other initiatives of the relaunched ParticipACTION resonated with inactive Canadians. ${ }^{39}$ Thus, consistent with the HOEM, we may have detected the cascade of cognitive and behavioural effects arising from the campaigns (e.g. people being aware of ParticipACTION and holding positive beliefs about LTPA, but not having changed their behaviour yet). Similarly, it is likely that people cycle in and out of awareness during the course of multi-year campaigns. ${ }^{40}$ Unfortunately, the cross-sectional nature of our study prevents us from determining whether these inactive Canadians will change their behaviour in the future. Another potential explanation for this shift in awareness is that the relaunched ParticipACTION focused much of its communication efforts, during 2007 and 2014, on the parents of inactive children. ${ }^{13}$ Thus, the organization's campaigns and messages may have resonated with Canadian adults who were not necessarily seeking to change their own physical activity, but rather that of their children. To address this explanation, we adjusted for child status in our logistic regressions and still found a negative association between LTPA status and awareness. Alternatively, the affective nature of these child-oriented messages and campaigns may have had broader reach and appeal than for parents alone (e.g. grandparents, teachers).

\section{Strengths and limitations}

Strengths of the study include the validated survey and sampling method from the long-running PAM surveillance system, the use of the same measures as were employed in 2007, and the application of a theoretical framework to guide the selection of questions and data analysis. However, this study is not without limitations that should be acknowledged. The use of single-item measures for self-efficacy, intention, and the awareness variables, along with the lower response rate, may limit the reliability of our findings. However, all of these measures have been employed in previous studies without problem ${ }^{14,15,39}$ and the self-efficacy measure is specific about the behaviour, the level of situational demand, and the time

TABLE 3

Weighted least squares means (standard errors) ${ }^{\text {a }}$ for physical activity related outcome expectations, self-efficacy, and intention by type of awareness for ParticipACTION

\begin{tabular}{|c|c|c|c|c|c|c|c|c|}
\hline & \multicolumn{4}{|c|}{ Unprompted awareness } & \multicolumn{4}{|c|}{ Prompted awareness } \\
\hline & Unaware & Aware & $\boldsymbol{F}$ & $\begin{array}{c}\text { Partial } \\
\eta \text {-squared }\end{array}$ & Unaware & Aware & $\boldsymbol{F}$ & $\begin{array}{c}\text { Partial } \\
\eta \text {-squared }\end{array}$ \\
\hline Self-efficacy & $5.88(0.03)$ & $5.69(0.05)$ & $13.93^{* * *}$ & 0.004 & $5.67(0.05)$ & $5.73(0.02)$ & 1.80 & 0.000 \\
\hline Intention & $6.12(0.03)$ & $6.17(0.04)$ & 0.66 & 0.000 & $5.99(0.04)$ & $6.07(0.02)$ & 0.04 & 0.000 \\
\hline
\end{tabular}

${ }^{a}$ Adjusted for gender and age.

*** $p<.0001$. 
TABLE 4

Adjusted and weighted odds ratios ${ }^{a}$ for factors associated with leisure time physical activity status by both prompted and unprompted awareness of ParticipACTION

\begin{tabular}{|c|c|c|c|c|c|c|c|c|c|c|c|c|}
\hline & \multicolumn{4}{|c|}{ Step 1} & \multicolumn{4}{|c|}{ Step 2} & \multicolumn{4}{|c|}{ Step 3} \\
\hline & $\boldsymbol{\beta}$ & Wald & OR & $95 \% \mathrm{Cl}$ & $\boldsymbol{\beta}$ & Wald & OR & $95 \% \mathrm{Cl}$ & $\boldsymbol{\beta}$ & Wald & OR & $95 \% \mathrm{Cl}$ \\
\hline \multicolumn{13}{|l|}{ Unprompted awareness } \\
\hline Awareness & -0.48 & 12.28 & 0.61 & $0.47-0.81^{* * *}$ & -0.20 & 7.37 & 0.70 & $0.50-0.89^{* *}$ & -0.21 & 8.54 & 0.65 & $0.48-0.87^{* *}$ \\
\hline Outcome expectations & & & & & 0.22 & 1.85 & 1.29 & $0.91-1.72$ & 0.09 & 0.27 & 1.10 & $0.77-1.56$ \\
\hline Self-efficacy & & & & & 0.58 & 90.10 & 1.80 & $1.59-2.03^{* * *}$ & 0.47 & 54.35 & 1.60 & $1.42-1.82^{* * *}$ \\
\hline Intention & & & & & & & & & 0.43 & 28.42 & 1.55 & $1.32-1.81^{* * *}$ \\
\hline \multicolumn{13}{|l|}{ Prompted awareness } \\
\hline Awareness & 0.0079 & 0.0013 & 1.01 & $0.66-1.55$ & -0.04 & 0.14 & 0.92 & $0.60-1.42$ & -0.04 & 0.16 & 0.92 & $0.60-1.39$ \\
\hline Outcome expectations & & & & & 0.18 & 2.21 & 1.20 & $0.94-1.53$ & 0.07 & 0.31 & 1.07 & $0.84-1.38$ \\
\hline Self-efficacy & & & & & 0.57 & 139.56 & 1.78 & $1.62-1.96^{* * *}$ & 0.45 & 85.86 & 1.58 & $1.43-1.73^{* * *}$ \\
\hline Intention & & & & & & & & & 0.47 & 55.78 & 1.60 & $1.42-1.81^{* * *}$ \\
\hline
\end{tabular}

Abbreviations: $\mathrm{CI}$, confidence interval; OR, odds ratio.

${ }^{a}$ Adjusted for gender, age, education, annual gross household income, and child status.

*** $p<.001$.

*** $p<.0001$.

frame as recommended by measurement experts. $^{41}$ As mentioned previously, the cross-sectional design prevents any discussion of cause and effect and limits the formal testing of the hierarchy of effects in the HOEM. While we were able to control for some demographic factors that may have accounted for the observed associations, other variables (such as perceived health status and immigrant status) may have been confounders for associations between intention and/or LTPA and awareness. Finally, we had no measure of media exposure or the depth of knowledge (i.e. actual message and contents) respondents had about ParticipACTION's campaigns. This type of information would provide more insight on the extent of the knowledge gap. ${ }^{42}$

\section{Conclusion}

Canadians continue to demonstrate high levels of awareness of ParticipACTION. Those who are aware of the organization are more likely to have children, and be inactive but hold positive beliefs about physical activity. The efforts of the relaunched ParticipACTION may have resonated with inactive Canadian adults through campaigns about children. Large knowledge gaps in awareness continue to be associated with levels of education and household income. Thus, future physical activity campaigns, programs, and policy initiatives should attempt to target different segments of the population, especially people who are disadvantaged.

\section{Acknowledgements}

Seven of the authors (JCS, GF, TB, SD, ALC, RR, MST) have served on the research advisory group for ParticipACTION. We are grateful to the Canadian Fitness Lifestyle and Research Institute (CFLRI) for allowing us to include questions about ParticipACTION on their Physical Activity Monitor (PAM). This project was made possible by an operating grant from the Canadian Institutes of Health Research (MOP-123491). GF holds a Canadian Institutes of Health Research-Public Health Agency of Canada (CIHR-PHAC) Chair in Applied Public Health. TB and ALC are both supported by the Canada Research Chairs Program.

\section{Conflicts of interest}

JS, GF, TB, SD, AER, RER and MST serve on the ParticipACTION Research Advisory Group.

\section{Authors' contributions and statement}

JCS conceptualized the design of the study, led the data analysis, and wrote the initial draft. CC led data collection and EYL contributed to analysis and writing. GF, TB, SD, AELC, RER, and MST provided input to study design, analysis, and interpretation, and in drafting and revising the paper. All authors have seen and approved the final manuscript.
The content and views expressed in this article are those of the authors and do not necessarily reflect those of the Government of Canada.

\section{References}

1. Colley RC, Garriguet D, Janssen I, Craig CL, Clarke J, Tremblay MS. Physical activity of Canadian adults: accelerometer results from the 2007 to 2009 Canadian Health Measures Survey. Health Rep. 2011;22(1):1-8.

2. Warburton DE, Bredin SS. Health benefits of physical activity: a systematic review of current systematic reviews. Curr Opin Cardiol. 2017;32:541-556. doi: 10.1186/1479-5868-7-40.

3. Manuel DG, Perez R, Sanmartin C, et al. Measuring burden of unhealthy behaviours using a multivariable predictive approach: life expectancy lost in Canada attributable to smoking, alcohol, physical inactivity, and diet. PLoS Med. 2016;13(8):e1002082. doi: 10.1371/journal.pmed.1002082.

4. Chetty R, Stepner M, Abraham S, et al. The association between income and life expectancy in the United States, 2001-2014. JAMA. 2016;315(16); 175066. doi: 10.1001/jama.2016.4226. 
5. Bounajm F, Dinh $\mathrm{T}$, Thériault $\mathrm{L}$. Moving ahead: the economic impact of reducing physical inactivity and sedentary behaviour. Ottawa $(\mathrm{ON})$ : The Conference Board of Canada; 2014 Oct 24. Available from: http:// sportmatters.ca/sites/default/files /content/moving_ahead_economic _impact_en.pdf

6. Cavill N, Bauman A. Changing the way people think about health-enhancing physical activity: do mass media campaigns have a role? J Sports Sci. 2004;22:771-90. doi: 10.1080/026404 10410001712467.

7. Leavy JE, Bull FC, Rosenberg M, Bauman A. Physical activity mass media campaigns and their evaluation: a systematic review of the literature 2003-2010. Health Educ Res. 2011:cyr069. doi: 10.1093/her/cyr069.

8. Abioye AI, Hajifathalian K, Danaei G. Do mass media campaigns improve physical activity? a systematic review and meta-analysis. Arch Pub Health. 2013;71(20):1-10. doi: 10.1186/0778 $-7367-71-20$.

9. Brown DR, Soares J, Epping JM, et al. Stand-alone mass media campaigns to increase physical activity: a community guide updated review. Am J Prev Med. 2012;43(5):551-61. doi: 10.1016/j.amepre.2012.07.035.

10. Heath GW, Parra DC, Sarmiento OL, et al. Evidence-based intervention in physical activity: lessons from around the world. Lancet. 2012;380(9838): 272-81. doi: 10.1016/50140-6736(12) 60816-2.

11. Costas-Bradstreet C. Spreading the message through community mobilization, education and leadership: a magnanimous task. Can J Pub Health. 2004;95(2 Suppl): S25-9.

12. Edwards P. No country mouse: thirty years of effective marketing and health communications. Can J Pub Health. 2004;95(2 Suppl):S6-13.

13. Faulkner G, Yun L, Tremblay MS, Spence JC. Exploring the impact of the 'New' ParticipACTION: overview and introduction of the special issue. Health Promot Chronic Dis Prev Can. 2018;38(4):153-61.
14. Bauman A, Madill J, Craig CL, Salmon A. ParticipACTION: This mouse roared, but did it get the cheese? Can J Pub Health. 2004 May 1; 95(2 Suppl):S14-9.

15. Spence JC, Brawley LR, Craig CL, et al. ParticipACTION: Awareness of the participACTION campaign among Canadian adults-examining the knowledge gap hypothesis and a hierarchy-of-effects model. Int $\mathrm{J}$ Behav Nutr Phys Act. 2009;6(85):1-9. doi: 10.1186/1479-5868-6-85.

16. Colley RC, Garriguet D, Janssen I, Craig CL, Clarke J, Tremblay MS. Physical activity of Canadian children and youth: accelerometer results from the 2007 to 2009 Canadian Health Measures Survey. Health Rep. 2011 ;22(1):15-23.

17. Berry TR, Craig CL, Faulkner G, et al. Mothers' intentions to support children's physical activity related to attention and implicit agreement with advertisements. Int $\mathrm{J}$ Behav Med. 2014;21 (1):131-8. doi: 10.1007/s12529 $-012-9279-5$.

18. Faulkner G, Solomon V, Berry T, et al. Examining the potential disconnect between parents' perceptions and reality regarding the physical activity levels of their children. JARC. 2014;5(1):1-29. Available from: http:// digitalcommons.library.tmc.edu/cgi /viewcontent.cgi?article $=1156 \&$ context $=$ childrenatrisk

19. Tremblay MS, Warburton DE, Janssen I, et al. New Canadian physical activity guidelines. Appl Physiol Nutr Metab. 2011;36(1):36-46. doi: 10.1139 /H11-009.

20. Gainforth HL, Jarvis JW, Berry TR, et al. Evaluating the ParticipACTION "Think Again" Campaign. Health Educ Behav. 2015; 43(4):434-441. doi: $10.1177 / 1090198115604614$.

21. Jarvis JW, Rhodes RE, Deshpande S, et al. Investigating the role of brand equity in predicting the relationship between message exposure and parental support for their child's physical activity. Soc Mark Q. 2014; 20(2):103-15. doi: $10.1177 / 1524500$ 414528183 .
22. Rhodes RE, Berry T, Craig CL, et al. Understanding parental support of child physical activity behavior. Am J Health Behav. 2013;37(4):469-77. doi: 10.5993/AJHB.37.4.5.

23. Rhodes RE, Spence JC, Berry T, et al. Predicting changes across 12 months in three types of parental support behaviors and mothers' perceptions of child physical activity. Ann Behav Med. 2015; 49(6):853-64. doi: 10.1007 /s12160-015-9721-4.

24. Rhodes RE, Spence JC, Berry T, et al. Understanding action control of parent support behavior for child physical activity. Health Psychol. 2016;35(2):131-40. doi: 10.1037 /hea0000233.

25. McGuire WJ. Public communication as a strategy for inducing health-promoting behavioral change. Prev Med. 1984;13:299-319.

26. Craig CL, Tudor-Locke C, Bauman A. Twelve-month impact of Canada on the Move: A population-wide campaign to promote pedometer use and walking. Health Educ Res. 2007;2: 406-13. doi: 10:1093/her/cyl093.

27. Craig CL, Cragg SE, Tudor-Locke C, Bauman A. Proximal impact of Canada on the Move: The relationship of campaign awareness to pedometer ownership and use. Can J Pub Health. 2006;97(1 Suppl):S21-7.

28. Taylor HL, Jacobs DR, Schucker B, Knudsen J, Leon AS, Debacker G. A questionnaire for the assessment of leisure time physical activities. J Chronic Dis. 1978;31(12):741-55.

29. Craig CL, Russell SJ, Cameron C, Bauman A. Twenty-year trends in physical activity among Canadian adults. Can J Pub Health. 2004:95(1);59-63.

30. Craney TA, Surles JG. Modeldependent variance inflation factor cutoff values. Qual Eng. 2002;14(3): 391-403. doi: 10.1081/QEN-120001878.

31. Latimer AE, Brawley LR, Bassett RL. A systematic review of three approaches for constructing physical activity messages: What messages work and what improvements are needed? Int J Behav Nutr Phys Act. 2010;7(36): 1-17. doi: 10.1186/1479-5868-7-36. 
32. Slater MD, Flora JA. Health lifestyles: Audience segmentation analysis for public health interventions. Health Educ Behav. 1991;18:221-33.

33. Gaziano C. The knowledge gap: an analytical review of media effects. Communication Research. 1983;10(4): 447-86.

34. Kwak N. Revisiting the knowledge gap hypothesis: education, motivation, and media use. Comm Res. 1999;26: 385-413. doi: 10.1177/00936509902600 4002 .

35. Cutler DM, Lleras-Muney A. Understanding differences in health behaviors by education. J Health Econ. 2010;29:1-28. doi: 10.1016/j.jhealeco .2009.10.003.

36. Piirtola M, Kaprio J, Kujala UM, et al. Association between education and future leisure-time physical inactivity: a study of Finnish twins over a 35-year follow-up. BMC Pub Health. 2016; 16(720):1-11. doi: 10.1186/s12889-016 $-3410-5$.

37. Spence JC, Faulkner G, Bradstreet CC, Duggan M, Tremblay MS. Active Canada 20/20: A physical activity plan for Canada. Can J Pub Health. 2016;106(8):E470-3. Available from: https://journal.cpha.ca/index.php /cjph/article/viewFile/5041/3278

38. Berry TR. Who's even interested in the exercise message? Attentional bias for exercise and sedentary-lifestyle related words. J Sport Exer Psych. 2006;28(1): 4-17. doi: 10.1123/jsep.28.1.4.

39. Craig CL, Bauman A, Latimer-Cheung $A$, et al. An evaluation of the "My ParticipACTION" campaign to increase self-efficacy for being more physically active. J Health Commun. 2015;20(9): 995-1003. doi: 10.1080/10810730.2015 .1012240 .

40. Leavy JE, Rosenberg M, Bull F, Bauman, A. Who do we reach? Campaign evaluation of Find Thirty every day ${ }^{\circledR}$ using awareness profiles in a Western Australian cohort. J Health Commun. 2014;19:853-869. doi: $10.1080 / 10810730.2013 .837560$.

41. Maibach E, Murphy DA. Self-efficacy in health promotion research and practice: conceptualization and measurement. Health Educ Res. 1995;10: 37-50. doi: 10.1093/her/10.1.37.
42. Kang Y. Knowledge gap effect in health campaign evaluations. $59^{\text {th }}$ Annual International Communications Association Conference, May 21-25; Chicago, Illinois. New York: ICA Press; 2009. Available from: http:// www.allacademic.com/meta/p11702_ index.html 